\title{
"The effects of entrepreneurial orientation on strategy choice and management control in nonprofit organizations"
}

\begin{tabular}{|c|c|}
\hline AUTHORS & $\begin{array}{l}\text { Stephanie Rüsch } \\
\text { Maik Lachmann } \text { (Dttps://orcid.org/0000-0002-5900-0895 } \\
\text { Maximiliane Wilkesmann (D https://orcid.org/0000-0001-7111-7554 } \\
\text { Karola Bastini }\end{array}$ \\
\hline ARTICLE INFO & $\begin{array}{l}\text { Stephanie Rüsch, Maik Lachmann, Maximiliane Wilkesmann and Karola Bastini } \\
\text { (2019). The effects of entrepreneurial orientation on strategy choice and } \\
\text { management control in nonprofit organizations. Problems and Perspectives in } \\
\text { Management, 17(3), 153-168. doi:10.21511/ppm.17(3).2019.13 }\end{array}$ \\
\hline DOI & http://dx.doi.org/10.21511/ppm.17(3).2019.13 \\
\hline RELEASED ON & Monday, 12 August 2019 \\
\hline RECEIVED ON & Wednesday, 22 May 2019 \\
\hline ACCEPTED ON & Thursday, 11 July 2019 \\
\hline LICENSE & $\begin{array}{l}(c) E Y \quad B \\
\text { This work is licensed under a Creative Commons Attribution } 4.0 \text { International } \\
\text { License }\end{array}$ \\
\hline JOURNAL & "Problems and Perspectives in Management" \\
\hline ISSN PRINT & $1727-7051$ \\
\hline ISSN ONLINE & $1810-5467$ \\
\hline PUBLISHER & LLC "Consulting Publishing Company "Business Perspectives" \\
\hline FOUNDER & LLC "Consulting Publishing Company "Business Perspectives" \\
\hline
\end{tabular}

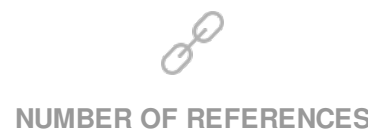

46
NUMBER OF FIGURES

1
NUMBER OF TABLES

5

(C) The author(s) 2022. This publication is an open access article. 


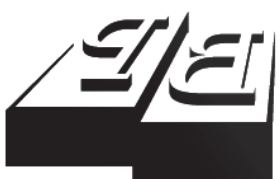

BUSINESS PERSPECTIVES

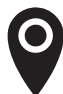

LLC "CPC "Business Perspectives" Hryhorii Skovoroda lane, 10, Sumy, 40022, Ukraine

www.businessperspectives.org

Received on: $22^{\text {nd }}$ of May, 2019 Accepted on: $11^{\text {th }}$ of July, 2019

(C) Stephanie Rusch, Maik Lachmann, Maximiliane Wilkesmann, Karola Bastini, 2019

Stephanie Rusch, Research Associate, Faculty of Business and Economics, Department of Sociology, TU Dortmund University, Germany.

Maik Lachmann, Full Professor, Accounting and Management Control, Faculty Economics and Management, Department of Accounting and Management Control, Technical University of Berlin, Germany.

Maximiliane Wilkesmann, Professor, Faculty of Sociology, Department of Sociology, TU Dortmund University, Germany.

Karola Bastini, Assistant Professor, Faculty Economics and Management, Department of Sustainability Accounting and Management Control, Technical University of Berlin, Germany.

\section{(ㄷ)(i)}

This is an Open Access article, distributed under the terms of the Creative Commons Attribution 4.0 International license, which permits unrestricted re-use, distribution, and reproduction in any medium, provided the original work is properly cited.

Stephanie Rüsch (Germany), Maik Lachmann (Germany),

Maximiliane Wilkesmann (Germany), Karola Bastini (Germany)

THE EFFECTS

OF ENTREPRENEURIAL ORIENTATION ON STRATEGY CHOICE AND MANAGEMENT CONTROL IN NONPROFIT ORGANIZATIONS

\begin{abstract}
In light of increasing relevance of strategic considerations in the nonprofit sector, this study investigates the entrepreneurial orientation of nonprofit CEOs and its linkage to strategic decision-making. The study provides initial insights into the types and effects of CEO entrepreneurial orientation, corresponding strategic choices, and differences in the implementation of strategies through managerial control in nonprofit organizations. Semi-structured expert interviews were conducted with the top managers of German nonprofit hospitals. The interviews were evaluated using qualitative content analysis. The findings are consistent with upper echelon theory, which considers management characteristics to be a determinant of strategic decision making, acting as a mediator between the external environment and strategic choices. The analysis in cludes two levels: (1) the entrepreneurial orientation of nonprofit CEOs at the individual level and (2) strategic choices on competitive strategies and their implementation at the organizational level. The findings show that the competitive environment evokes different types of entrepreneurial orientation that influence the approach of nonprofit CEOs to strategic decisions and implementation processes. Highly entrepreneurial CEOs prefer prospector strategies over defender or reactor strategies. CEOs with low levels of entrepreneurial orientation tend to use controls diagnostically, whereas CEOs exhibiting medium to high levels of entrepreneurial orientation use controls interactively. This study extends the existing literature by providing evidence of the types of managerial entrepreneurial orientation in nonprofit organizations and the resulting effects on strategic planning and implementation processes. This paper thus sheds light on a key determinant of strategic decision-making and implementation in nonprofit organizations.
\end{abstract}

Keywords

\section{JEL Classification M12, M40, L31}

\section{INTRODUCTION}

Nonprofit organizations play an important role in modern economies (Morris et al., 2011). In a traditional major field such as healthcare, they compete with for-profit market participants and face the challenge of coping with changing market conditions in increasingly competitive environments. The concept of entrepreneurial orientation is of special interest here, since it captures the degree to which an organization develops new solutions and advances their implementation, and thereby is able to gain strategic advantages over its competitors (Miller, 1983; Lumpkin \& Dess, 1996). To continuously and effectively serve their social mission, nonprofits have to develop competitive strategies and monitor strategy implementation by means of managerial control. 
However, the profit-oriented concepts of entrepreneurial orientation, strategy and management control need to be adjusted to the specific characteristics of nonprofit organizations (Morris et al., 2011; Moore, 2000). Furthermore, in hierarchical and comparatively small organizations such as nonprofit hospitals, the influence of top managers - also referred to as upper echelons - on strategic choices (Hambrick \& Mason, 1984) needs to be considered.

This paper intends to contribute to the upper echelon theory, strategy, and management control literature on the nonprofit sector in several ways. First, we investigate dimensions of entrepreneurial orientations of nonprofit CEOs, i.e., we advance a concept that has been widely used in management research based on a setting with specific corporate governance characteristics. Second, we analyze how entrepreneurial orientation influences competitive strategies applied in nonprofit organizations (Miles \& Snow, 1978; Miles et al., 1978) and thereby shed light on the mediating role of CEO characteristics on the relationship between environmental settings and strategies in the nonprofit sector. Third, we investigate whether managers with different entrepreneurial orientations differ in their application of management control systems (Simons, 1995) in implementing their strategies. Our study is explorative in nature and uses semi-structured interviews with top managers of German nonprofit hospitals. Additionally, the business reports and websites of the hospitals were analyzed.

The remainder of this paper is structured as follows. In section 1, we develop our research question based on theoretical considerations and the existing literature. In section 2, the empirical methodology is explained. Findings are presented in section 3 and discussed in section 4. Last section concludes.

\section{LITERATURE REVIEW, THEORETICAL CONSIDERATIONS AND RESEARCH QUESTION}

Upper echelon theory argues that strategic outcomes are influenced by top managerial characteristics (Hambrick \& Mason, 1984). In the hospital setting, top management characteristics such as age, personal background, education, and work experience have been reported to affect strategic choices and implementation (De Harlez \& Malagueño, 2016; Morelli \& Lecci, 2014; Abernethy et al., 2010; Naranjo-Gil, 2009; Burkert \& Lueg, 2013). Very little attention has been devoted to the specific context, both in terms of industry and profit orientation status, which are likely to influence these relationships (Hiebl, 2014). In addition, the effects of underlying individual attitudes of top managers have been neglected.

Entrepreneurial orientation as a managerial attitude describes proactiveness, innovativeness, and willingness to take risks (Miller, 1983). The concept of entrepreneurial orientation has been addressed in various studies focusing on industrial contexts (Miller, 2011; Naldi et al., 2007). In the nonprofit context, diverse and potentially conflicting stakeholder interests need to be balanced, so that entrepreneurial orientation becomes a more multifaceted and complex construct, taking the social purpose into account in each of its dimensions (Morris et al., 2007, 2011). An adaptive managerial entrepreneurial orientation is a potentially crucial attribute of nonprofit CEOs for successfully coping with adverse market prerequisites. This assumption seems particularly reasonable for organizations where CEOs exert a strong influence on strategic decisions due to lean organizational management structures. Therefore, this paper investigates which consequences result from different levels of entrepreneurial orientation of nonprofit CEOs for the choice of strategies and management control. Figure 1 describes the research model that serves as a framework for the analysis.

In response to increasing competitive pressure induced by regulatory reforms, hospitals have striven to achieve distinct strategic positioning vis-àvis competing hospitals (Bazzoli et al., 2004). The framework of strategic typologies developed by Miles and Snow (1978) divides hospitals into different organizational types: prospectors, analyzers, defenders and reactors (Short et al., 2002; Kober et al., 2007; Helmig et al., 2014). However, empir- 


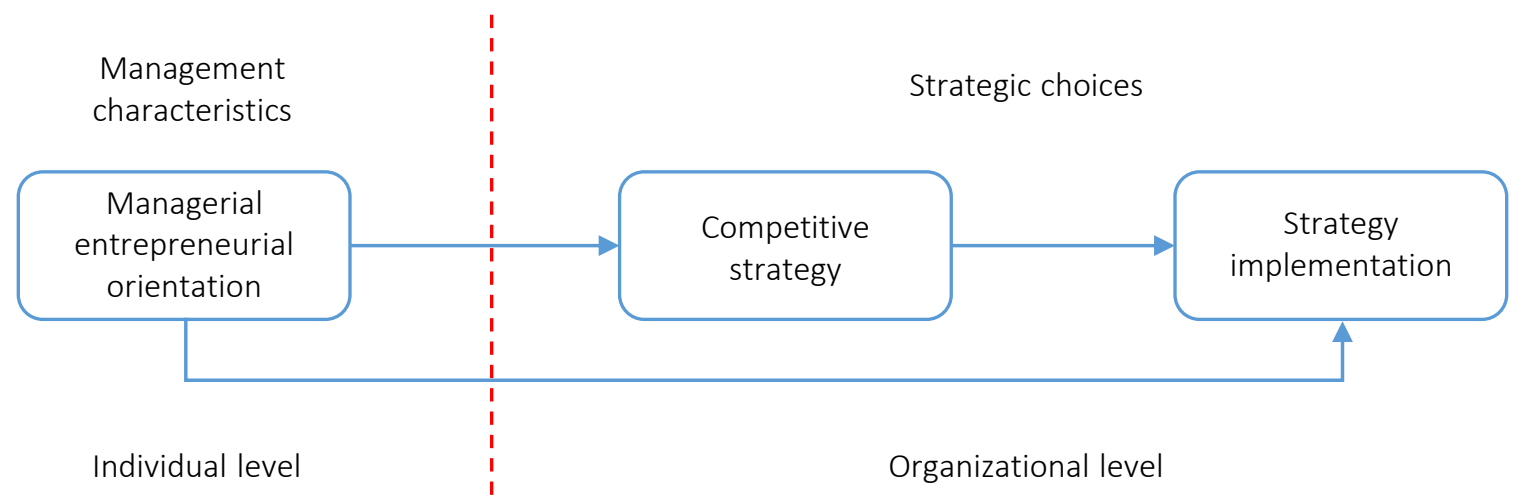

Figure 1. Research model

ical evidence on how CEO attitudes determine those strategic directions of hospitals is scarce. Management control systems serve as a means for implementing organizational strategies. The most widely applied classification of management controls is the levers of control framework, which distinguishes between diagnostic and interactive uses of control (Henri, 2006; Simons, 1995). Whereas diagnostic use is a negative force that ensures compliance with rules by establishing constraints, interactive use represents a positive trigger of creativity, featuring informal norms of cooperation and open communication channels (Henri, 2006; Mundy, 2010). Management controls are shaped by internal determinants (Chenhall, 2003). For example, Naranjo-Gil and Hartmann (2007b) find that hospital CEOs with a clinical (administrative) background prefer an interactive (diagnostic) mode of control. While tight output controls imposed on professional staff by administrative managers spur conflicts between professional and bureaucratic values (Abernethy \& Stoelwinder, 1995), the formal integration of physicians in management structures increases their cost consciousness (Abernethy \& Vagnoni, 2004).

Furthermore, the balanced use of diagnostic and interactive controls (Mundy, 2010) is of particular interest. While diagnostic controls ensure cost containment or budget restrictions, interactive controls may be of strategic importance regarding the involvement of physicians who possess relevant professional knowledge. Investigating the effects of managerial entrepreneurial orientation on the balanced use of control, therefore, constitutes a valuable extension of the related management control literature.

\section{METHODOLOGY}

To explore our research question from multiple angles, we (1) conducted semi-structured expert interviews with nonprofit hospital managers and (2) collected additional information from corresponding hospital websites.

We conducted interviews with 10 CEOs and 3 administrative directors of nonprofit hospitals from December 2013 to April 2014. The hospitals examined are situated in a densely populated and thus highly competitive region of Germany. In Germany, as in many other countries, most nonprofit hospitals are owned by the church and represent traditional actors in the market due to their Christian history (Risse, 1999). They face particular societal expectations in terms of the ethical treatment of their stakeholders, including patients and personnel (Hull \& Lio, 2006). These specific features are expected to affect the managing of collective goods in nonprofit organizations. The case, therefore, stands representative for nonprofit healthcare organizations in other central European countries that are rooted in a similar historical tradition.

We applied purposive sampling, aiming at covering a wide range of possible competitive prerequisites (see Table 1). One main challenge involved gaining access to hospital CEOs who were expected to have the greatest influence on strategies. In three cases, we were referred to administrative directors who occupy hierarchical positions directly beneath hospital CEOs (for simplicity, these are subsumed under the term CEO in the following). After conducting 13 interviews, our theoretical questions seemed to be answered to a suffi- 
Table 1. Description of sample

\begin{tabular}{|c|c|c|c|c|c|}
\hline Hospital no. & Hospital size & Location & $\begin{array}{c}\text { Competitive } \\
\text { pressure* }\end{array}$ & $\begin{array}{l}\text { Position of } \\
\text { respondent }\end{array}$ & $\begin{array}{c}\text { Duration of interview } \\
\text { (minutes) }\end{array}$ \\
\hline 1 & Small & Urban & Medium & Adm. director & 17 \\
\hline 2 & Medium & Urban & High & CEO & 31 \\
\hline 3 & Small & Urban & High & Adm. director & 35 \\
\hline 4 & Medium & Urban & Medium & CEO & 54 \\
\hline 5 & Large & Urban & High & CEO & 28 \\
\hline 6 & Medium & Urban & High & CEO & 61 \\
\hline 7 & Medium & Rural & Low & Adm. director & 23 \\
\hline 8 & Medium & Urban & High & CEO & 79 \\
\hline 9 & Small & Urban & Medium & CEO & 77 \\
\hline 10 & Medium & Urban & High & CEO & 57 \\
\hline 11 & Large & Urban & Medium & CEO & 31 \\
\hline 12 & Medium & Rural & Low & CEO & 30 \\
\hline 13 & Medium & Rural & Medium & CEO & 28 \\
\hline
\end{tabular}

Note: * To determine the competitive pressure for each hospital, the adjacent hospitals in a radius of $30 \mathrm{~km}$ were counted. The competitive pressure is labeled as "high" if there are more than 65 adjacent hospitals, "medium" between 35 and 65 , and "low" in the case of fewer than 35 hospitals in a radius of $30 \mathrm{~km}$.

cient extent, and we obtained interesting results. Therefore, we decided at that point to complete the picture drawn from the interviews by an additional analysis of the hospitals' mission statements.

The semi-structured interview guide included initial questions regarding the qualification and prior work experience of hospital CEOs to collect information on management characteristics considered in related upper-echelon studies. Next, competitive strategies were looked at in terms of strategic objectives, perceived impeding aspects, and competitive pressure. Through these aspects, we were able to categorize the hospitals in terms of the Miles and Snow (1978) typology (see Appendix A, Tables A2 and A4). The entrepreneurial orientation of CEOs was evaluated based on questions regarding the type of actions taken to implement strategy and the design of planning processes. To avoid the promotion of socially desirable answers, we did not directly address the term of entrepreneurial orientation. Instead, by letting the interviewees speak freely about their roles in strategic processes, we gained insight into their entrepreneurial attitudes. Finally, the monitoring of strategy implementation processes, based on performance measurement and incentive systems, was discussed (see Appendix A, Table A1). Thereby, we drew conclusions with regard to the interactive and diagnostic use of controls (Simons, 1995).

Regarding the second data source (the hospital websites), we collected information on the special- ized clinics, interdisciplinary medical centers, and mission statements of the examined hospitals. The intention was to gather additional data on their strategies to complement the statements made by the interviewees. As a result, we gained a deeper understanding of hospital strategies used.

We analyzed the interviews by means of a structuring qualitative content analysis (Mayring, 2015). The purpose of this form of analysis is to classify text material into deductive categories (see Appendix A, Table A2), allowing the researcher to evaluate the examined text based on predetermined criteria. On the individual level of our research model (Figure 1), we interpreted the statements of the interviewees with respect to their individual attributes (i.e., their entrepreneurial orientation). The codes used for entrepreneurial orientation were based on a widely acknowledged approach (Miller, 1983; Lumpkin \& Dess, 1996; Kreiser et al., 2002; Covin \& Wales, 2012; Morris et al., 2011) that operationalizes organizational entrepreneurial orientation in terms of proactiveness, innovativeness, and risk taking. To evaluate individual (as opposed to organizational) entrepreneurial orientations, we drew on recognized individual-level definitions for these three dimensions. Proactiveness applies when respondents "scan for opportunities, show initiative, take action, and persevere until they reach closure by bringing about change" (Bateman \& Crant, 1993, p. 105). An innovator is someone "who (1) introduces new goods or services; (2) introduces new 
methods of production; (3) operates new markets; (4) finds new sources of raw materials; and/or (5) carries out new organization of any industry" (Robinson et al., 1991, p. 20; Schumpeter, 1934). Risk taking involves "the perceived probability of receiving the rewards associated with success of a proposed situation, which is required by an individual before he will subject himself to the consequences associated with failure, the alternative situation providing less reward as well as less severe consequences than the proposed situation" (Brockhaus, 1980, p. 513).

To evaluate the intensity of the entrepreneurial orientation of each interviewee, we applied a scaling qualitative content analysis (Mayring, 2015). This approach acts as an instrument for evaluating categories or dimensions on an ordinal scale. To this end, we determined manifestations of the three dimensions of entrepreneurial orientation (low, medium, and high) and added corresponding definitions, coding rules and examples for each manifestation (see Appendix A, Table A3). As a result, we assigned a distinct degree of entrepreneurial orientation to each interviewee.

At the organizational level, we analyzed (factual) information on organizational strategies that the respondents used in their role as experts. In addition, we analyzed data from the hospital websites to characterize each hospital in terms of prospective or defensive strategic elements. For instance, a hospital citing a narrow medical focus (a small number of specialized departments), few interdisciplinary medical centers and a strong cost orientation in its mission statement was considered to act as a strategic defender. A hospital offering wide-ranging medical services (diversified specialized departments), comprehensive medical center structures, and a clear preference for innovations was labeled a prospector. The mission statements of these hospitals cited, e.g., a willingness to actively engage in competition, foster innovation, and act as a pioneer in terms of innovative medical services.

To ensure the quality of our data and methodology, the categories and coding rules were discussed among an interdisciplinary research team in terms of consensual validation (Hill et al., 1997). In addition, the multiple data sources used enhance validity through data triangulation (Erlandson et al., 1993). We tested the reliability of the coding results by having a second person (from outside the research team) code the interview material. In the independent coding rounds, an intercoder-reliability of $80 \%$ was obtained.

\section{FINDINGS}

\subsection{Individual level - management characteristics}

The introductory questions concerning the interviewees' individual careers reveal that most often, hospital CEOs hold a university degree in business administration (5 CEOs) or completed a scientific and practical medical education (2 CEOs). One physician holds an additional university degree in health economics. Interestingly, we also met lateral entrants with educational backgrounds in social or political sciences. Amongst CEOs with a background in business administration, most exhibit professional experience from outside the hospital sector, such as in the consulting, tax and auditing sector, or from directing business companies.

Regarding CEO entrepreneurial orientation, the respondents exhibited proactiveness more often than innovativeness and risk taking. A proactive attitude is manifested in several ways. On the one hand, the interviewees emphasized an urge to anticipate medical developments to introduce unique novelties faster than competing hospitals. Similarly, they attempt to detect growth opportunities before their competitors (e.g., through mergers) to improve their negotiating position vis-à-vis other institutions (e.g., health insurance companies): "Through size, you become more interesting to negotiating partners. (...) If we hadn't done this [the merger], another one would have done it. Then, another one would have received the strength that we have today (Exp. 2)".

Correspondingly, the nonprofit hospital is regarded as an "economical enterprise" (Exp. 3) that seeks to "do a good job in the future" (Exp. 3). In this context, strategic planning is perceived as an active process that is reflected in everyday business: "We work on our strategy every day. You 
can't say we do it twice a year or five times a year. Any day that we don't work on our strategy is a wasted day (Exp. 2)".

A challenge associated with this process concerns finding a balance between forward-looking strategic planning and preserving the capacity to respond to sudden changes: "This means, on the one hand, finding a balance between planned action by saying "OK, let's go ahead with this" and, on the other hand, still being flexible and not getting carried away (Exp. 10)”.

On the other hand, some interviewees mention regulatory effects of the state that hinder proactive choices. For instance, Exp. 1 states that pursuing unique strategies is quite difficult, as hospital strategies are heavily shaped by legislation and by mandates to provide care. Hence, by alleging that corporate strategies cannot be affected by individual actors, he cited a negative form of proactive and thus reactive - behavior.

Innovativeness was exhibited less frequently than proactiveness in the interviews. For example, Exp. 2 expresses his openness regarding new ideas forwarded either by himself or by chief physicians: "I love ideas, and I often come up with new ideas. However, our chief physicians also come up with new ideas. They simply say, "I've got a new idea." (...) and then we talk about it and look at the market, conduct calculations, and quickly come to a decision (Exp. 2)".

In conjunction with this innovative attitude, some hospitals have introduced suggestion systems that allow employees to contribute to innovative projects (Exp. 9). Furthermore, the exchange of creative ideas among experts through a "think tank consisting of internal executives of the medical field, the CEO, administration and five external [experts]" (Exp. 2) reflects a strong willingness to adopt innovations.

We could hardly find evidence on risk-taking behavior in the interviews. Remarkably, negative manifestations of this dimension were detected. For instance, Exp. 8 states that hospitals intend to "substantially change structures"; however, they "simply do not possess a sufficient surplus to be able to say that we conduct experiments or to see if we can afford to waste half a million" (Exp. 8).
Similarly, Exp. 7 explains that competitive pressures on hospitals severely undermine their scope of action: "The other issue is: How big is the need? If the water is up to my neck, then I'm not worrying about the next five years, as I'm thinking about how I will survive the next month. Many hospitals are in the position to say: "I am just before the exit." Then, a long-term strategy is useless; I have to make sure that I survive (Exp. 7)".

Therefore, prior to committing to a significant investment, external market developments and internal economic consequences of investments are thoroughly analyzed. Comprehensive scenario analyses are used in such contexts (Exp. 2), pointing to a strong emphasis on reducing risks through the careful consideration of potential consequences related to investment decisions.

In comparing the interviewed experts in terms of manifested entrepreneurial orientations, three groups can be identified: relatively high (Exp. 2, 5, 8, 10), medium (Exp. 3, 4, 6, 7, 9, 11, 12), and low (Exp. 1, 13) levels of entrepreneurial orientation. Interestingly, with regard to the personal characteristics of CEOs that upper echelon theory is referring to, those experts who exhibit a high degree of managerial entrepreneurial orientation in our study more often show professional experience from outside the hospital sector (e.g., in private firms). CEOs with a medical background showed medium or high entrepreneurial orientation.

\subsection{Organizational level - strategic choices}

To explore the relationship between the entrepreneurial orientation of hospital CEOs and strategic choices, this study draws on Miles and Snow's (1978) strategic typology. However, one aspect of this framework is neglected (the analyzer), as all of the hospitals showed features of analysis. For example, prior to entering a new medical field, they had carried out comprehensive internal and external assessments to estimate their chances of successful market entry. To obtain distinct strategy types, our study focuses on the remaining three prospectors, reactors, and defenders.

Our findings indicate that highly entrepreneurial hospital CEOs tend towards prospector strat- 
egies, medium-level entrepreneurs tend towards defender strategies, and low-level entrepreneurs tend towards reactor strategies (see Appendix A, Table A4). The hospitals showing clear indications of prospector strategies (Hosp. 2, 5, 10, $11,12)$ operate several specialized clinics and medical centers. The strategic targets declared in their mission statements include entering new medical fields (Hosp. 11), facing the challenges of modern medicine (Hosp. 2), or being a pioneer in medical care (Hosp. 5). In most of these hospitals, the CEOs exhibit a highly entrepreneurial orientation. The hospitals that apply defender strategies (Hosp. 3, 4, 6, 7, 8, 9, 13) are mostly run by moderate entrepreneurs. They set their strategic focus on the optimization of internal processes (Hosp. 13) and on maintaining facilities and employees (Hosp. 9), whereas economic success is perceived as "necessary" to achieve organizational objectives (Hosp. 6). The CEO of one hospital applying a reactor strategy (Hosp. 1) exhibits a low degree of individual entrepreneurial orientation. This hospital operates few clinics with a narrow focus, runs no medical centers, and cites no particular strategy in its mission statement.

While both prospector and defender hospitals may be run by entrepreneurial CEOs, the object of entrepreneurial behavior differs: entrepreneurial CEOs of prospector hospitals focus on enhancing their services or markets, whereas entrepreneurial CEOs of defender hospitals focus on (proactive and innovative) ways to improve their services and the efficiency of their processes.

For the group with the lowest entrepreneurial orientation, strategic decision-making is not perceived as a proactive process but rather as a necessity that results from emerging market structures. Growing competition between hospitals is viewed as a threat that must be mitigated. These features point towards a reactive strategy type. In reference to this context, Exp. 1 describes state restrictions that interfere with strategic positioning: "We are active in the field of healthcare, and in my opinion, hospital strategies are extremely affected by legislation and by the mandate to provide care. This implies that personal strategies are not prioritized. The priority is to preserve the economic efficiency of each hospital (Exp. 1)".
This statement conflicts with the overall perception that by introducing regulatory reforms, the state has actually given more strategic responsibility to hospitals and thus more room to use dynamic market structures. Exp. 13, in contrast, recognizes the need to take strategic action, but he would prefer that the state assume a more dominant stance in hospital strategic planning. By taking more intervening action, the state could reduce competition between hospitals.

A new hospital planning framework for 2015 has been launched in our federal state; the government retracts from detailed planning processes. Now the floodgates are open for competition. Many people say "Now everyone can simply do whatever they want [in terms of medical treatment]." The regulatory influence of the state is basically missing (Exp. 13).

Concerning strategy implementation, CEOs with low entrepreneurial orientation tend to focus on diagnostic targets, such as "achieving predefined budgets" (Exp. 1). Similarly, performance is predominantly measured by diagnoses related groups (DRG)-based figures. As an explanation for this confining use of management control, Exp. 1 refers to financial restrictions that are imposed on hospitals, stating that DRGs finance the entire hospital. However, indications of the interactive use of control were also found. Exp. 13, for example, states that strategic papers produced in a strategy workshop are available to interested employees on the Intranet to foster transparency. Nevertheless, he explains that these online publications are hardly referenced by a number of employees and therefore do not necessarily lead to any significant effects in terms of common strategy alignment. This example shows that the use of interactive control occurs, but it is not sophisticated enough (yet) to motivate personnel to work towards a common goal.

For the group with a moderate level of entrepreneurial orientation, the respondents did not emphasize any particular efforts to be at the forefront of new services. The focus is rather on maintaining existing services at the regional scale. Exp. 12 explains that they are restricted by budgets and thus "cannot choose the number of inpatients at will", thus emphasizing the need to cope with exist- 
ing regional market conditions. Because external market conditions cannot be influenced directly, they focus on refining internal processes to reduce costs while preserving a relatively stable set of services. Accordingly, Exp. 7 stresses the importance of providing specialized offers to support efforts to reduce costs, forming one of the hospital's main strategic objectives: "The objective is to reduce (...) fixed costs in the surgical ward, for example, by providing specialized offers at each hospital location. [We try] to centralize fixed costs for personnel and expensive medical equipment while basing one field of expertise at each location (Exp. 7)".

Consistent with the defender strategy, a particular market segment is focused. Exp. 12 explains that the hospital seeks to cooperate with other hospitals in the region to coordinate their range of services to avoid redundant cost structures: "We try to refine each medical service offer, and this implicates different measures to the effect that we attempt to cooperate with other regional hospitals, perhaps to coordinate with them on service offers so that there are no redundant service offers, as this has a very strong impact on the business structure (Exp. 12)".

Corresponding to this regional focus, potential cooperation partners, particularly regarding mergers, are identified within the proximity of their own hospital: "We have the goal to create local networks. We do not believe that there are any reasons to enter a national network with a partner hospital in a distant region. Instead, we think it is important to have a partner in our region, forming a strong local network that generates synergy effects and that supports the same ideologies (Exp. 4)".

In spite of these defensive strategies, the CEOs do exhibit entrepreneurial orientation, yet on a different scale than their prospective counterparts. Whereas the CEOs of prospector hospitals direct their entrepreneurial orientation towards entering new markets and offering new services, the CEOs of defender hospitals express their entrepreneurial attitudes by improving existing services and processes. For instance, Exp. 9 plans to establish a "ward cockpit" that unites case managers from all disciplines. Instead of having a separate process for each ward a patient is treated on, interdisciplinary case managers generate codes for each treat- ment, complete physician letters and inform physicians of treatments in their cross-departmental functions. This process structure is novel to this hospital. However, the purpose of this innovation is to increase internal process quality and the efficiency of existing offers and is thus a defender strategy.

For CEOs with a moderate level of entrepreneurial orientation, the diagnostic use of controls prevails as well. Targets such as reducing fixed costs (Exp. 7), meeting budgets (Exp. 7, 9, 11) and performance measurement through DRG-based figures (Exp. 4, 7, 11, 12) are mentioned. However, within this restrictive frame, opportunities to create interactivity are realized. For example, Exp. 12 uses data from the InEK (federal institute for the German hospital sector compensation system) calculation as a benchmark for departments (diagnostic use). Because these figures are transparent and accepted by heads of departments, they serve as a basis for professional discussion in cases of disagreement (interactive use): "We think that the InEK calculation is a good tool for benchmarking individual departments. (...) The departments sometimes argue about who actually has the higher share of sales. In these cases, the numbers [of the InEK calculation] are accepted, and commitments to them have evolved, as they are the basis for our remuneration. I can thus now discuss this with our heads of department (Exp. 12)".

Similarly, Exp. 9 states that he regards the recently introduced cost-unit accounting system (diagnostic use) as a means to foster transparency (interactive use). In reference to this, he emphasizes the importance of ensuring high data quality to generate credibility: “(...) so the physicians say "I believe [the CEO] now." Then, I can converse with them on a different level than if they said "[The numbers] that you have gathered are not transparent; they are not credible" (Exp. 9)".

Finally, the respondents with high entrepreneurial orientation focus on anticipating future market developments in regards to strategic planning, thus adopting a prospective strategy. They outcompete other hospitals by being the first to embrace promising opportunities. This is reflected in proactive and innovative entrepreneurial attitudes: "We constantly monitor our competitors 
and medical developments in the disciplines we offer. (...) When competitors are manageable with regards to quality, we try to be a bit better than the others and eliminate our competitors. We monitor the development of each department. Where does medicine evolve in a particular department? Then, we try to get faster with our implementation to be more creative than others on the market simply in order to acquire unique characteristics (Exp. 2)".

In spite of external restrictions, e.g., through health insurance funds, a future-oriented strategy that focuses on expanding medical services is pursued. Again, a proactive attitude along with a willingness to innovate serves as a motivator.

Another feature reflected in the strategies implemented by highly entrepreneurial CEOs is an openness towards changes in the hospital's organizational structure. Particularly, the establishment of medical centers is considered to enhance the quality of services and to facilitate a coordinated treatment of patients (Exp. 10, Exp. 5). Furthermore, highly entrepreneurial CEOs exhibit a willingness to engage in co-operations and mergers to achieve synergies and coordinate the provision of services (Exp. 8). Opportunities are sought not only on a regional scale, but also on a supra-regional scale: "This is stated in our strategic plan: Regional providers with transregional priorities (...). When acquiring new hospitals, we do not select any hospitals that we cannot relate to [strategically] or that do not have their own unique characteristics; they must have at least one (Exp. 10)".

In the group with a high entrepreneurial orientation, the integration of both diagnostic and interactive uses of controls, and thus a balanced use, prevails. It seems that hospital CEOs with high entrepreneurial orientation tend to involve their employees in the strategy implementation process on a larger scale than CEOs who belong to the moderate group. Remarkably, a particular emphasis is placed on free communication and information flow. For instance, Exp. 8 has had a number of conversations with responsible persons to reduce skepticism in budget discussions. He especially underscores the importance of bilateral communication: "The first budget talks (...) were rather anxiety provoking. (...) However, after conduct- ing them repeatedly for two or three months, [the physicians] realized that this is a customary way to discuss cost issues. We can now talk about this and identify causes of [cost deviations], and when there is a reasonable explanation, perhaps this is somehow OK (Exp. 8)".

A broad-scale involvement of employees in the target-setting process is described by Exp. 10. He encourages his physicians to discuss common standards in professional groups that include members of different hospitals, thus fostering organizational learning: "We have task groups in every department. This means that all orthopedic surgeons meet and vascular surgeons and internists meet and discuss the benchmarks. What use is a benchmark if I cannot talk about why it is different? [The task groups] set common standards for further development. At first, it was about sizing each other up, but now they have really grown together (Exp. 10)".

Regarding the organizational culture and leadership skills involved in strategy implementation, Exp. 5 emphasizes the importance of management abilities: "If chief physicians or managers do not share a vision, if they don't have a strategy, people are unable to follow. You might as well have employees then, but, I believe, you will not realize their full potential, which you might need (Exp. 5)".

Throughout the interviews, CEOs with a high entrepreneurial orientation, when reflecting on strategic goal setting, cited Christian values as a common vision or belief system that is guiding decisions besides economic considerations. For instance, Exp. 5 states that one advantage of a confessional nonprofit hospital is the ability to follow common values in the provision of health services that are not financed in alternative contexts. Due to the missing shareholder value orientation, higher standards regarding the quality of services provided and a different weight placed on patient care are expected (Exp. 10, Exp. 5). Similarly, a common Christian belief system should be reflected in a respectful interaction and working relationship with the hospital's employees (Exp. 10).

Regarding possible conflicts between economic constraints and Christian values, Exp. 8 gets to 
the heart of the issue by stating: "In fact, it has always been this way. When I manage resources well, I can serve more patients with it. I still don't feel like we lack work in the healthcare sector. (...) we may face the problem that we are not provided with the money we (claim to) need. But that means we should strive not to waste money. This seems ethical to me. (...) I do not see a contradiction but a community of values here. We should be aware of this (Exp. 8)".

\section{DISCUSSION}

Our results show that CEOs of hospitals situated in a particularly pressured and competitive environment predominantly belong to the group with high entrepreneurial orientation. High standards of medical and nursing services based on the newest technologies are considered vital to increasing revenues. However, only proactive CEOs are able to identify the most promising innovative technologies, such as Artificial Intelligence (Vuong et al., 2019; Jiang et al., 2017), and/or new customer segments early enough to realize competitive advantages. Furthermore, the factors that influence patient choices, e.g., the patients' cost consciousness (Vuong et al., 2018) and various patient-related and organizational factors (see Victoor et al., 2012 for a comprehensive review), need to be considered. According to our results, the entrepreneurial orientation of hospital CEOs seems to have an effect on strategic decisions while being triggered by a competitive environment, suggesting that an entrepreneurial orientation may mediate the effects of the regulatory hospital market and of strategic choices made within organizations.

CEOs with low levels of entrepreneurial orientation tend to adopt rather reactive strategies, whereas CEOs who show high levels of entrepreneurial orientation are prone to using prospector strategies. CEOs exhibiting moderate levels of entrepreneurial orientation tend towards defender strategies. These results extend the findings of the previous studies that emphasize the influence of top management characteristics on strategies in the hospital sector (De Harlez \& Malagueño, 2016; Naranjo-Gil \& Hartmann, 2007a). Our study is novel in revealing the underlying motivations of hospital CEOs in mak- ing distinct strategic choices that may not be explained by previously addressed personal characteristics.

Regarding strategy implementation, CEOs with low levels of entrepreneurial orientation tend to use controls diagnostically, whereas CEOs exhibiting medium to high levels of entrepreneurial orientation use them interactively. These findings conflict with Naranjo-Gil and Hartmann (2007b) who state that administrative (clinical) hospital managers prefer a diagnostic (interactive) use of control. According to our results, entrepreneurial hospital CEOs cope with budgetary constraints (diagnostic use of control) by extensively involving their chief physicians in the strategy implementation process (interactive use of control). This positive relationship between entrepreneurial orientation and an interactive use of control might be associated with the physicians' powerful position within hospitals (Freidson, 2001). Particularly with regards to their emphasis on implementing medical innovations ahead of their competitors, entrepreneurial hospital CEOs depend on the expertise of their clinicians and on their willingness to share relevant information with them.

Furthermore, highly entrepreneurial CEOs successfully balance interactive and diagnostic control types (Mundy, 2010), which positively affects strategy implementation. In contrast, hospital CEOs with moderate or low levels of entrepreneurial orientation tend to focus primarily on diagnostic controls and therefore apply less-balanced control systems. In the examined hospitals, this has resulted in rather low involvement of physicians and nurses in strategy implementation and less organizational learning. CEO entrepreneurial orientation thus constitutes an additional factor that affects an organization's ability to balance control systems.

While the conflict between bureaucratic and professional values has been investigated in previous studies (Abernethy \& Vagnoni, 2004), our study provides initial empirical evidence of possible synergetic effects between both approaches (Morris et al., 2011). Our respondents emphasized ethical aspects of the nonprofit orientation, which implies cooperative and respectful interactions with stakeholders, especially with patients and clinical 
staff. In several highly entrepreneurial hospitals, patient satisfaction is monitored and the results are used in performance evaluation processes. In one case, quality management results are moni- tored in cross-functional teams and translated into improvement projects. This mission orientation supports entrepreneurial attitudes in the studied hospitals.

\section{CONCLUSION AND IMPLICATIONS}

The findings in this study are subject to typical limitations of field studies. The limited number of interviews conducted does not allow us to draw generalizable conclusions in a statistical sense. However, the qualitative research method enabled us to explore strategic decision making in German nonprofit hospitals, including motivations behind hospital CEOs' strategic actions.

This exploratory study provides a number of avenues for future research. Additional management characteristics as determinants of entrepreneurial orientation in the hospital sector could be explored. Although studies that analyze entrepreneurial behavior discuss determinants such as the locus of control, the need for achievement and the tolerance of ambiguity (Entrialgo et al., 2000), evidence on this issue is missing for the unique nonprofit hospital market setting. Furthermore, investigating CEO entrepreneurial orientation across hospital ownership types may shed additional light on the results obtained here for positive synergies between a common value system and profit-orientation, a relationship that has been characterized as conflictual in prior literature.

Our results have several implications for hospital practice. Owners of nonprofit hospitals should consider CEO entrepreneurial orientations in recruiting processes (e.g., by analyzing their professional experiences or previous actions in organizations) when intending to pursue a certain strategic orientation. Furthermore, our findings point to a lack of interactive controls applied by hospital CEOs with low or moderate levels of entrepreneurial orientation. Because related studies report positive effects of interactive controls on cost reduction (Naranjo-Gil, 2009), these control types may also assist with the implementation of defender strategies, e.g., through joint initiatives between CEOs and (chief) physicians in reducing resource consumption. Our results, therefore, may motivate hospital CEOs to apply management controls more interactively.

With regards to the regulatory perspective, the prevalence of prospective strategies and entrepreneurial orientation among hospital CEOs suggests that nonprofit hospitals align their corporate governance mechanisms with those of for-profit hospitals. These effects may appear positive in light of a more effective and efficient healthcare system. However, regulators should note that these developments could also eliminate diversity in the hospital market, which may have negative effects on healthcare quality and on patient choices in the long run.

\section{REFERENCES}

1. Abernethy, M. A., Bouwens, J., \& Van Lent, L. (2010). Leadership and control system design. Management Accounting Research, 21(1), 2-16. https://doi. org/10.1016/j.mar.2009.10.002

2. Abernethy, M. A., \& Stoelwinder, J. U. (1995). The role of professional control in the management of complex organizations. Accounting, Organizations and Society, 20(1), 1-17. https://doi. org/10.1016/0361-3682(94) E0017-O

3. Abernethy, M. A., \& Vagnoni, E. (2004). Power, organization design and managerial behavior. Accounting, Organizations and Society, 29(3-4), 207-225. https://doi.org/10.1016/S03613682(03)00049-7

4. Bateman, T. S., \& Crant, J. M. (1993). The proactive component of organizational behavior: A measure and correlates. Journal of Organizational Behavior, 14(2), 103-118. https://doi.org/10.1002/ job.4030140202

5. Bazzoli, G. J., Dynan, L., Burns, L. R., \& Yap, C. (2004). Two decades of organizational change in health care: what have we learned? Medical Care Research and Review, 61(3), 247-331. https://doi. org/10.1177/1077558704266818 
6. Brockhaus, R. H. (1980). Risk taking propensity of entrepreneurs. Academy of Management Journal, 23(3), 509-520. http://dx.doi. org/10.2307/255515

7. Burkert, M., \& Lueg, R. (2013). Differences in the sophistication of value-based management: the role of top executives. Management Accounting Research, 24(1), 3-22. https://doi.org/10.1016/j. mar.2012.10.001

8. Chenhall, R. H. (2003) Management control systems design within its organizational context: findings from contingency-based research and directions for the future. Accounting, Organizations and Society, 28(2/3), 127-168. https://doi.org/10.1016/S03613682(01)00027-7

9. Covin, J. G., \& Wales, W. J. (2012). The measurement of entrepreneurial orientation. Entrepreneurship Theory and Practice, 36(4), 677-702. https:// doi.org/10.1111\%2Fj.15406520.2010.00432.x

10. De Harlez, Y., \& Malagueño, R. (2016). Examining the joint effects of strategic priorities, use of management control systems, and personal background on hospital performance. Management Accounting Research, 30, 2-17. https://doi.org/10.1016/j. mar.2015.07.001

11. Entrialgo, M., Fernández, E., \& Vázquez, C. J. (2000). Characteristics of managers as determinants of entrepreneurial orientation: some Spanish evidence. Enterprise and Innovation Management Studies, 1(2), 187-205. http://dx.doi. org/10.1080/14632440050119596

12. Erlandson, D. A., Harris, E. L., Skipper, B. L., \& Allen, S. D. (1993). Doing Naturalistic Inquiry. A Guide to Methods. SAGE Publications, Newbury Park, CA.

13. Freidson, E. (2001). Professionalism, the Third Logic. On the Practice of Knowledge. University of Chicago Press, Chicago.
14. Hambrick, D. C., \& Mason, P. A. (1984). Upper echelons: the organization as a reflection of its top managers. Academy of Management Review, 9(2), 193-206. Retrieved from https:// papers.ssrn.com/sol3/papers. cfm?abstract_id=1504456

15. Helmig, B., Hinz, V., \& Ingerfurth, S. (2014). Extending Miles \& Snow's strategy choice typology to the German hospital sector. Health policy, 118(3), 363-376. https://doi.org/10.1016/j.healthpol.2014.06.006

16. Henri, J.-F. (2006). Management control systems and strategy: A resource-based perspective. Accounting, Organizations and Society, 31(6), 529-558. https://doi. org/10.1016/j.aos.2005.07.001

17. Hiebl, M. R. W. (2014). Upper echelons theory in management accounting and control research. Journal of Management Control, 24(3), 223-240. Retrieved from https://link.springer.com/article/10.1007/s00187-013-0183-1

18. Hill, C. E., Thompson, B. J., \& Williams, E. N. (1997). A guide to conducting consensual qualitative research. The Counseling Psychologist, 25(4), 517-572. https://doi.org /10.1177\%2F0011000097254001

19. Hull, C., \& Lio, B. (2006). Innovation in non-profit and for-profit organizations: visionary, strategic, and financial considerations. Journal of Change Management, 6(1), 53-65. Retrieved from https:// www.researchgate.net/publication/247505468_Innovation_in_ non-profit_and_for-profit_organizations_Visionary_strategic_and_ financial_considerations

20. Jiang, F., Jiang, Y., Zhi, H., Dong, Y., Li, H., Ma, S., Dong, Q., Shen, H.,. \& Wang, Y. (2017). Artificial intelligence in healthcare: past, present and future. Stroke and vascular neurology, 2(4), 230-243. https://doi.org/10.1136/svn-2017000101

21. Kober, R., Ng, J., \& Paul, B. J. (2007). The interrelationship between management control mechanisms and strategy.
Management Accounting Research, 18(4), 425-452. https://doi. org/10.1016/j.mar.2007.01.002

22. Kreiser, P. M., Marino, L. D., Kuratko, D. F., \& Weaver, K. M. (2013). Disaggregating entrepreneurial orientation: the non-linear impact of innovativeness, proactiveness and risk-taking on SME performance. Small Business Economics, 40(2), 273-291. https://doi.org/10.1007/ s11187-012-9460-x

23. Kreiser, P. M., Marino, L. D., \& Weaver, K. M. (2002). Assessing the psychometric properties of the entrepreneurial orientation scale: a multi-country analysis. Entrepreneurship Theory and Practice, 26(4), 71-94. https://doi.org/10.1177\% 2F104225870202600405

24. Lumpkin, G. T., \& Dess, G. G. (1996). Clarifying the entrepreneurial orientation construct and linking it to performance. Academy of Management Review, 21(1), 135172. https://doi.org/10.2307/258632

25. Mayring, P. (2015). Qualitative Inhaltsanalyse. Grundlagen und Techniken. Beltz, Weinheim and Basel.

26. Miles, R. E., \& Snow, C. C. (1978). Organizational strategy, structure, and process. McGraw-Hill, New York.

27. Miles, R. E., Snow, C. C., Meyer, A. D., \& Coleman, Jr. H. J. (1978). Organizational strategy, structure, and process. Academy of Management Review, 3(3), 546-562. https://doi.org/10.2307/257544

28. Miller, D. (1983). The correlates of entrepreneurship in three types of firms. Management Science, 29(7), 770-791. Retrieved from https://www.jstor.org/ stable/2630968?seq=1\#page_scan_ tab_contents

29. Miller, D. (2011). A reflection on EO research and some suggestions for the future. Entrepreneurship Theory and Practice, 35(5), 873-894. https://doi.org/10.1111\%2Fj.15406520.2011.00457.x

30. Moore, M. F. (2000). Managing for value: organizational strategy 
in for-profit, nonprofit, and governmental organizations. Nonprofit and Voluntary Sector Quarterly, 29(1), 183-204. https:// doi.org/10.1177\%2F08997640002 915009

31. Morelli, M., \& Lecci, F. (2014). Management control systems (MCS) change and the impact of top management characteristics: the case of healthcare organisations. Journal of Management Control, 24(3), 267-298. Retrieved from https:// link.springer.com/article/10.1007/ s00187-013-0182-2

32. Morris, M. H., Coombes, S., Schindehutte, M., \& Allen, J. (2007). Antecedents and outcomes of entrepreneurial and market orientations in a non-profit context: theoretical and empirical insights. Journal of Leadership and Organizational Studies, 13(4), 12-39. https://doi.org/10.1177\% 2F10717919070130040401

33. Morris, M. H., Webb, J. W., \& Franklin, R. J. (2011). Understanding the manifestation of entrepreneurial orientation in the nonprofit context. Entrepreneurship Theory and Practice, 35(5), 947-971. https:// doi.org/10.1111\%2Fj.15406520.2011.00453.x

34. Mundy, J. (2010). Creating dynamic tensions through a balanced use of management control systems. Accounting, Organizations and Society, 35(5), 499-523. https://doi.org/10.1016/j. aos.2009.10.005
35. Naldi, L., Nordqvist, M., Sjöberg, K., \& Wiklund, J. (2007). Entrepreneurial orientation, risk taking, and performance in family firms. Family Business Review, 20(1), 33-47. https:// doi.org/10.1111\%2Fj.17416248.2007.00082.x

36. Naranjo-Gil, D. (2009). Strategic performance in hospitals: The use of the balanced scorecard by nurse managers. Health Care Management Review, 34(2), 161-170. https://doi.org/10.1097/ HMR.0b013e31819e8fd0

37. Naranjo-Gil, D., \& Hartmann, F. (2007a). Management accounting systems, top management team heterogeneity and strategic change. Accounting, Organizations and Society, 32(7-8), 735-756. https://doi.org/10.1016/j. aos.2006.08.003

38. Naranjo-Gil, D., \& Hartmann, F. (2007b). How CEOs use management information systems for strategy implementation in hospitals. Health Policy, 81(1), 29-41. https://doi.org/10.1016/j. healthpol.2006.05.009

39. Risse, G. B. (1999, December). Health care in hospitals: the past 1000 years. The Lancet, 354, 25. Retrieved from https://www.thelancet.com/pdfs/journals/lancet/ PIIS0140673699903689.pdf

40. Robinson, P. B., Stimpson, D. V., Huefner, J. C., \& Hunt, H. K. (1991). An attitude approach to the prediction of entrepreneurship. Entrepreneurship Theory and Practice, 15(4), 13-30. https://doi.org/10.1177\% 2F104225879101500405

41. Schumpeter, J. (1934). The theory of economic development. Cambridge MA: Harvard University Press.

42. Short, J. C., Palmer, T. B., \& Ketchen, D. J. Jr. (2002). Resource-based and strategic group influences on hospital performance. Health Care Management Review, 27(4), 7-17. Retrieved from https://www.ncbi. nlm.nih.gov/pubmed/12433243

43. Simons, R. (1995). Levers of control: How managers use innovative control systems to drive strategic renewal. Harvard Business School Press, Boston.

44. Victoor, A., Delnoij, D. M. J., Friele, R. D., Rademakers, J. J. D. J. M. (2012). Determinants of patient choice of healthcare providers: a scoping review. $B M C$ Health Services Research, 12, 272.

45. Vuong, Q. H., Ho, T. M., Nguyen, H. K., \& Vuong, T. T. (2018). Healthcare consumers' sensitivity to costs: A reflection on behavioural economics from an emerging market. Palgrave Communications, 4(1), 70.

46. Vuong, Q. H., Ho, M. T., Vuong, T. T., La, V. P., Ho, M. T., Nghiem, K. C. P., ... \& Ho, C. S. (2019). Artificial Intelligence vs. Natural Stupidity: Evaluating AI Readiness for the Vietnamese Medical Information System. Journal of Clinical Medicine, 8(2), 168. 


\section{APPENDIX A}

Table A1. Semi-structured interview guide

\begin{tabular}{|c|c|}
\hline Superordinate questions and aspects to request & Main aspects covered relating to research question \\
\hline $\begin{array}{l}\text { A) What is the strategy of your hospital? } \\
\text { - Strategic objectives } \\
\text { - Aspects impeding the strategy } \\
\text { - Perceived competitive pressure }\end{array}$ & Strategy of the hospital (organizational level) \\
\hline $\begin{array}{l}\text { B) Which actions do you take to implement the strategy? } \\
\text { C) Long-term/short-term } \\
\text { C) Ho you plan the strategy? } \\
\text { - Persons involved } \\
\text { - Procedure of strategy planning } \\
\text { - Time horizons }\end{array}$ & Entrepreneurial orientation (individual level) \\
\hline $\begin{array}{l}\text { D) How do you monitor the implementation of the strategy? } \\
\text { - Performance measurement } \\
\text { - Incentive system }\end{array}$ & Use of control \\
\hline
\end{tabular}

Table A2. List of deductive codes

\begin{tabular}{|c|c|c|}
\hline Level & Category & Code \\
\hline \multirow{5}{*}{ Individual level } & \multirow{2}{*}{ Demographical aspects } & Qualification \\
\hline & & Work experience \\
\hline & \multirow{3}{*}{ Managerial entrepreneurial orientation } & Proactiveness \\
\hline & & Innovativeness \\
\hline & & Risk taking \\
\hline \multirow{8}{*}{ Organizational level } & \multirow{4}{*}{ Strategic orientation } & Prospector \\
\hline & & Analyzer \\
\hline & & Defender \\
\hline & & Reactor \\
\hline & \multirow{4}{*}{ Strategy implementation } & Performance measurement \\
\hline & & Incentives \\
\hline & & Diagnostic use of control \\
\hline & & Interactive use of control \\
\hline
\end{tabular}

Table A3. Coding guidelines for managerial entrepreneurial orientation

\begin{tabular}{|c|c|c|c|}
\hline Category & Manifestation & Definition & Examples \\
\hline \multirow{3}{*}{ Innovativeness } & $\begin{array}{l}\text { High level of } \\
\text { innovativeness }\end{array}$ & $\begin{array}{l}\text { - Innovation is not only new to the } \\
\text { hospital but new to the market } \\
\text { and/or } \\
\text { - Innovation requires substantial } \\
\text { (financial) investment }\end{array}$ & $\begin{array}{l}\text { - Has invested in a new treatment } \\
\text { technology which is novel to the } \\
\text { market (Exp. 2) } \\
\text { - Engages in cooperation with } \\
\text { airports to enter new markets } \\
\text { (foreign patients) (Exp. 9) }\end{array}$ \\
\hline & $\begin{array}{l}\text { Medium level of } \\
\text { innovativeness }\end{array}$ & $\begin{array}{l}\text { - Innovation is new to the hospital, } \\
\text { but already established on the } \\
\text { market } \\
\text { and/or } \\
\text { - Innovation does not require } \\
\text { substantial investments }\end{array}$ & $\begin{array}{l}\text { - Has established suggestion } \\
\text { management, employees are } \\
\text { encouraged to share ideas (Exp. } \\
\text { 13) } \\
\text { - Runs a radio show to attract/ } \\
\text { inform patients, following the } \\
\text { example set by a competitor (Exp. } \\
\text { 10) }\end{array}$ \\
\hline & $\begin{array}{l}\text { Low/no level of } \\
\text { innovativeness }\end{array}$ & $\begin{array}{l}\text { - Innovation is not perceived as } \\
\text { necessary } \\
\text { and/or } \\
\text { - No innovations mentioned }\end{array}$ & $\begin{array}{l}\text { - Focuses on reducing costs, not } \\
\text { on implementing suggestions by } \\
\text { physicians (Exp. 6) } \\
\text { - Actions of competitors are no } \\
\text { reason to implement new ideas } \\
\text { (Exp. 10) }\end{array}$ \\
\hline
\end{tabular}


Table A3 (cont.). Coding guidelines for managerial entrepreneurial orientation

\begin{tabular}{|c|c|c|c|}
\hline Category & Manifestation & Definition & Examples \\
\hline \multirow{3}{*}{ Proactiveness } & High level of proactiveness & $\begin{array}{l}\text { - Proactive actions require substantial } \\
\text { investments } \\
\text { - Tries to influence aspects that are } \\
\text { hardly changeable } \\
\text { - Actions change the structure/ } \\
\text { processes of the hospital in an } \\
\text { fundamental way } \\
\text { - Searches for sustainable solutions }\end{array}$ & $\begin{array}{l}\text { Decisions on medical care need } \\
\text { to be taken by the hospitals } \\
\text { themselves, not by politicians } \\
\text { (Exp. 2) } \\
\text { - Actively builds up sustainable } \\
\text { structures of mutual } \\
\text { communication (Exp. 4) } \\
\text { - Has developed a management } \\
\text { cockpit (Exp. 11) }\end{array}$ \\
\hline & $\begin{array}{l}\text { Medium level of } \\
\text { proactiveness }\end{array}$ & $\begin{array}{l}\text { - Actions are taken, but do not require } \\
\text { substantial investments } \\
\text { and/or } \\
\text { - Actions are not initiated, if } \\
\text { conditions are hardly changeable } \\
\text { and/or } \\
\text { - Actions are not necessarily } \\
\text { sustainable }\end{array}$ & $\begin{array}{l}\text { - Conducts one-on-one } \\
\text { conversation with chief physicians } \\
\text { on a regular basis for consultation } \\
\text { (Exp. 3) } \\
\text { - Initiates cooperation with } \\
\text { hospitals on a regional scale to } \\
\text { benefit from economies of scale } \\
\text { (Exp. 12) }\end{array}$ \\
\hline & $\begin{array}{l}\text { Low/no level of } \\
\text { proactiveness }\end{array}$ & $\begin{array}{l}\text { - No particular manifestation of } \\
\text { proactive actions }\end{array}$ & $\begin{array}{l}\text { - Emphasizes inability to change } \\
\text { cost or to influence cost } \\
\text { determinants due to regulatory } \\
\text { compensation system (Exp. 1) }\end{array}$ \\
\hline \multirow{3}{*}{ Risk taking } & High level of risk taking & $\begin{array}{l}\text { High perceived possibility of } \\
\text { receiving the rewards associated } \\
\text { with success of a risky situation }\end{array}$ & $\begin{array}{l}\text { Emphasizes expected benefits } \\
\text { from the purchase of an } \\
\text { innovative, costly machine which } \\
\text { is new to the hospital and to the } \\
\text { region (Exp. 2) }\end{array}$ \\
\hline & $\begin{array}{l}\text { Medium level of risk } \\
\text { taking }\end{array}$ & $\begin{array}{l}\text { Possibility of receiving the rewards } \\
\text { associated with success of a } \\
\text { risky situation is considered, but } \\
\text { possible negative consequences are } \\
\text { mentioned as well }\end{array}$ & $\begin{array}{l}\text { - Invests in new projects, but tests } \\
\text { them in small hospitals of the } \\
\text { holding before implementing } \\
\text { them in every hospital (Exp. 10) }\end{array}$ \\
\hline & Low/ no level of risk taking & $\begin{array}{l}\text { - High perceived possibility of } \\
\text { negative consequences associated } \\
\text { with failure of a risky situation } \\
\text { and/or } \\
\text { - Emphasis on extensive market } \\
\text { analyses prior to investment }\end{array}$ & $\begin{array}{l}\text { - Hesitancy towards building up } \\
\text { new structures, emphasizes the } \\
\text { related costs (Exp. 12) }\end{array}$ \\
\hline
\end{tabular}

Table A4. Managerial entrepreneurial orientation and hospital strategies

\begin{tabular}{|c|c|c|c|}
\hline $\begin{array}{l}\text { Hospital } \\
\text { no. }\end{array}$ & $\begin{array}{l}\text { Intensity of managerial } \\
\text { entrepreneurial orientation }\end{array}$ & $\begin{array}{l}\text { Characteristics of hospital strategy based on } \\
\text { organizational structure and mission statement }\end{array}$ & Strategy type elements \\
\hline 1 & Low & $\begin{array}{l}\text { Few specialized departments which focus on surgery/ } \\
\text { orthopedics } \\
\text { No particular strategy mentioned, except cooperation } \\
\text { with regional hospitals and resident doctors }\end{array}$ & Reactor/defender \\
\hline 2 & High & $\begin{array}{l}\text { Highly diversified departments (incl. East Asian medicine) } \\
\text { High number of interdisciplinary centers } \\
\text { Face challenges of modern medicine } \\
\text { Are convinced that in spite of the necessity of making } \\
\text { plans, there must be room for the unexpected and } \\
\text { spontaneity }\end{array}$ & Prospector \\
\hline 3 & Medium & $\begin{array}{l}\text { Small number of departments } \\
\text { One center in which resident doctors can operate } \\
\text { Target is to provide local population with qualitative } \\
\text { medical offer }\end{array}$ & Defender \\
\hline 4 & Medium & $\begin{array}{l}\text { Medium number of specialized departments and medical } \\
\text { centers } \\
\text { Focus on cooperation with regional hospitals and resident } \\
\text { doctors }\end{array}$ & Defender/prospector \\
\hline
\end{tabular}


Table A4 (cont.). Managerial entrepreneurial orientation and hospital strategies

\begin{tabular}{|c|c|c|c|}
\hline $\begin{array}{l}\text { Hospital } \\
\text { no. }\end{array}$ & $\begin{array}{c}\text { Intensity of managerial } \\
\text { entrepreneurial orientation }\end{array}$ & $\begin{array}{l}\text { Characteristics of hospital strategy based on } \\
\text { organizational structure and mission statement }\end{array}$ & Strategy type elements \\
\hline 5 & High & $\begin{array}{l}\text { Medium number of departments and centers } \\
\text { Targets are to face new challenges, foster innovations and } \\
\text { not remain passive in the face of seemingly unchangeable } \\
\text { conditions } \\
\text { Aim to be a pioneer }\end{array}$ & Prospector \\
\hline 6 & Medium & $\begin{array}{l}\text { Numerous diversified departments and medical centers } \\
\text { (incl. Tele-medicine) } \\
\text { Focus on corporate marketing } \\
\text { Economic success perceived "necessary" to achieve } \\
\text { objectives }\end{array}$ & Defender/prospector \\
\hline 7 & Medium & $\begin{array}{l}\text { Medium number of departments and one center in which } \\
\text { resident doctors can operate } \\
\text { Focus on one particular service, within this core } \\
\text { competency application of differentiated technology }\end{array}$ & Defender \\
\hline 8 & High & $\begin{array}{l}\text { Medium number of diversified departments and medical } \\
\text { centers (incl. East Asian medicine and sports medicine) } \\
\text { Continuous optimization and development of services and } \\
\text { facilities }\end{array}$ & Defender/prospector \\
\hline 9 & Medium & $\begin{array}{l}\text { Small number of departments and centers } \\
\text { Focus on efficient processes to reduce costs } \\
\text { Target is to hold on to employees and facilities }\end{array}$ & Defender \\
\hline 10 & High & $\begin{array}{l}\text { Numerous diversified departments and centers } \\
\text { Focus on corporate marketing to communicate unique } \\
\text { selling proposition } \\
\text { High number of medical and non-medical cooperation } \\
\text { partners }\end{array}$ & Prospector \\
\hline 11 & Medium & $\begin{array}{l}\text { High number of departments and centers, incl. one } \\
\text { innovative center which is the first of its kind in Germany } \\
\text { Adapts range of services by entering new medical fields }\end{array}$ & Prospector \\
\hline 12 & Medium & $\begin{array}{l}\text { High number of diversified departments and medical } \\
\text { centers } \\
\text { Focus on refining internal processes } \\
\text { High number of cooperation partners, incl. Medicine, } \\
\text { education and sports }\end{array}$ & Defender/prospector \\
\hline 13 & Low & $\begin{array}{l}\text { Small number of departments and centers } \\
\text { Focus on one medical field } \\
\text { Target consists in optimization of processes and } \\
\text { cooperation with regional partners }\end{array}$ & Defender \\
\hline
\end{tabular}

